\title{
Big Data Drive Tourism Enterprises Integration Innovation
}

\author{
Guo-Hong CHEN \\ Management College, Shenyang Normal University, Shenyang,110034/Huang He Bei Street No.253, China \\ guohong_c@sina.com
}

\begin{abstract}
Big data affects the integration of innovative products and services of tourist enterprises. Tourist enterprises are in urgent need of integration innovation as it becomes the source of competitive advantage. In the era of big data, integration innovation in tourist enterprise can impacted from several factors: large data mining analysis, strategy of tourist development, integration of innovative resources and capabilities, etc. Tourism enterprises should leverage big data to build a large tourist data analysis system, by focusing on integration of large data and valuation and exploring internal and external models tourist enterprises.
\end{abstract}

\section{Literature Review}

The concept of big data was originated by Peter (1960) as data science. Toffler (1980) predicted in "Third Wave" that society will enter the era of big data. Bill (1990) proposed the concept of "massive data". In twenty-first century, big data is getting more attention[1-3]. A report from McKinsey (2011) suggests that big data has penetrated into every field of industries and business functions and is becoming an important factor for productivity[4]. Research from Brown (2011) pointed out that big data can bring game-changing impact[5]. Christina (2013) believes that big data has the power of creative destruction for current business model. Rapid development of big data reflects part of human's continuous exploration process[6].

Integration innovation was first introduced by Rosenberg (1963), who noted that integration innovation takes place when similar technologies are applied across different industries. Greenstein (1998) categorized integration innovation into three modes, i.e. replacement, complementary and combination. Morgan (2004) proposed a model to combine internal and external technology integration.

China scholars have also conducted in-depth research in this area. Zhang Yanxing (1996), Meng Qingwei (2003) and Hu Chunxiang suggested that integration innovation, i.e. introduction, digestion, absorption and recreation, is the key processes by which an enterprise obtain and consolidate external advanced technology and experience. Liu Xin (2006) concluded that integration innovation focuses more on the impact of innovation and its long term competitiveness. Li Ping (2013) proposed that integration innovation can be defined as combining new technologies from different fields for the development process of new technology and process and system.

Big data and integration innovation have made a huge impact the supply and demand balance of tourist industry. Olsen, Moore (1998), Law (2000) Buhalis (2002) have shown that big data technology and information is changing function of tourist distribution channels by providing value-added services. Fesenmaier (2000) and Frew (2004) believe that big data can help tourist enterprises with a wide range of promotional activities to supplement offline promotion activities. Xu Hong and fan Qing (2008) pointed out that innovation is the driving force for the convergence of tourist industry. Liu Yuqing (2009) proposed that deep penetration of big data into the tourist enterprises has changed the management mode. Ma Xue Feng (2010) proposed integration is to actively introduce relevant technology from other industries with technical advantages into tourist enterprises. Liu Xueting (2011) believes that technology integration is an important catalyst for tourist enterprise integration and innovation. Yang Yanfeng (2012) believes that big data is driving the integration of tourism industry. Gao Lingjiang and Xia Changjie (2012) also believe that technology innovation brings system management and product market innovation into tourist enterprises and eventually change the mode of tourist enterprises development.

In practice, although experts and scholars proposed various definitions, description, concept, and impact of big data and integration innovation, current research focuses more on qualitative analysis on macroscopic scale. Microscopic quantitative research on the impact of big data and integration innovation is limited. There is a lack of research on the impact of big data on the nature of integration innovation. For many tourist enterprises, the interest in big data remains as abstract 
and theoretical; therefore it is either lack of practical operation or applicable to only specific cases. The absence of systematic research leads to the fact that limited research has had very little impact in guiding the introduction and innovation of tourist product and services. Potential impact of big data on tourist product and service needs to be explored, in particular in conjunction with integration innovation, so that forward-looking principles can be established to guide tourist enterprises. It is also important to reveal these principles with the power of big data to identify hidden characteristics and trends that are common to tourist enterprises.

\section{Tourist Enterprises Based on Big Data and Integration Innovation}

\subsection{Analysis of Large Data Mining in Tourist Enterprises}

Acquisition and analysis of big data for tourist enterprises is closely related to business process such as product design, channel selection, price formulation, and strategy. Tourist enterprises can collect and analyze consumer information to extract information on consumer need, consumer concern and hot topics, and specifics such as consumption and spending behavior. Further analysis of consumer behavior can lead to potential new customer, design and development of tourism products, marketing and sales activities.

For example, construction of high-speed rail in a city provides a quick and easy way of transportation. Neighboring cities can now be connected with the high-speed rail, and tourist flow between these cities will be impacted. Studies using spatial econometric model shows that construction of high-speed rail can have spatial spillover effect on neighboring cities. A spatial spillover effect is defined as the impact of social and economic activity of one city on surrounding cities. High speed rail has positive spatial spillover effect as it facilitates long-distance travel and promotes long distance tourism. However, a negative spatial spillover effect exists if there is competition for tourist flow between these cities. As such tourist enterprises can analyze tourist information in real time to identify and develop marketing strategy to deal with positive or negative spillover flow.

\subsection{Development Strategy of Tourist Enterprises}

With big data processing technology becoming more and more mature and perfection, tourist enterprises should get better at using big data for reform and innovation. New business models such as Ctrip, LY, Piaoguanjia are being introduced by large and medium-sized tourist enterprises via leveraging large data collection, intelligent tourism and industry restructuring. In the era of big data, the tourist enterprises can objectively analyze consumer behavior with high accuracy. At the same time, tourist enterprises can depend on big data analysis to support enterprise strategy development to adapt to change.

In the process of formulating development strategy, on the one hand, the tourist enterprises can perform consumer data mining with special focus on tourist demand, consumption need, interconnectivity, and consumer feedback. The enterprise can make decision about tourist consumption behavior and value orientation. On the other hand, in marketing and sales process, tourist enterprises can use big data to monitor corresponding attention, interest, active contraction, action and sharing strategy. Big data analysis can guide tourist business strategy to better serve consumers and expand market share.

\subsection{Integration Innovation Resources and Capabilities for Tourist Enterprise}

Tourist market information is an important resource for the integration innovation. Tourist enterprises face the new challenge of how to use of these resources to promote growth and integrate innovation for decision-making. By analyzing and understanding the dynamics of market trend, tourist enterprises can better forecast tourist market, preferences and spatial distribution of tourist flow, and facilitate the restructuring and combination for upstream and downstream integration. Since big data can provide comprehensive historical and cross-border perspective, it is advantage to use the data as a platform to create value and expand market and enhance services. Through the analysis of consumer behavior and tourist psychology, future tourist industry can be expected to provide corresponding products and services.

Comparing with traditional tourist enterprise data analysis and management, big data analysis is more focused on the extension of the external data, overall market trend analysis and prediction, and these can positively affect the tourist enterprise information system, data processing ability, management mode and so on. At the same time, the value of isolated data is far less than that of widely correlated data; the value of collective data is far greater than that of a single type of data.

\section{Strategies for Integration Innovation}

\subsection{Construction of Large Tourism Data Analysis System}

\subsubsection{Macro environment of tourist industry}

First, it begins with data collection and analysis on external tourist environment data, including external macro economy, regional development, tourism consumption patterns, and tourism competitiveness. Secondly, it includes comparison of area traffic, such as mode of transportation by aviation, railway, waterway 
and highway. Furthermore, it is clearly advantageous to include quantitative analysis of regional tourist characteristics, climate information, and other tourist resources. Finally, it must include tourist resource, core tourist market, potential market status, analysis of regional competition.

\subsubsection{Regional tourist market segmentation}

Analysis includes tourist age, gender, education level, occupation, income, behavior. Distribution of tourist information, behavior, collection mode, attention to special location, time duration at scenic spots, travel related dynamic machine, etc.

\subsubsection{Supervision system of tourist market}

Supervision system include monitoring regional tourist market, tourist flow, early warning, hot spots, hot search, tourist flow prediction, hot spots distribution; Public opinion to scenic tourist reputation evaluation, emotional volatility, positive and negative feedback, public opinion warning mechanism.

\subsection{Integration and Valuation of Big Data}

\subsubsection{Integration of big data}

Correlation analysis by integration of big data from different industries can promote the development of cross-border tourism and accelerate the pace of integration innovation. Tourist enterprises and enterprises from related industries can share information and resources for in-depth analysis of market information to understand consumption pattern and tourists preference for market trend forecast. For example, by integrating real estate development and seals information with local tourist market data, tourist products and market development can be designed to meet the needs and preferences of new households.

\subsubsection{Valuation of blg data}

Big data is an important cornerstone for innovative products and innovative business models. Big data helps building new business models. Tourist enterprises value big data as a capital of the enterprise and use large data analysis to forecast tourist business model innovation and to create new profit growth. Unlike typical corporate valuation, the data information is enterprise resources and capital and has market value. Economists agree that big data is an intangible asset.

The commercial value of big data includes two aspects. First it can help tourist enterprises to reduce cost and improve productivity. Secondly, it helps tourist enterprises to better segment and position tourist market, such as data analysis, product design, better meet customer need, improving core competitiveness, value creation.

\section{Integration Innovation System of Tourist Enterprises}

Using big data allows construction of a new type of tourist enterprises completely. Internally, tourist enterprise can qualitatively predict market trend by changing from traditional upstream and downstream organization to integration of various different industries sharing and analyzing the data on product design. Tourist enterprises themselves are transformed into consumer and supplier of big data. Externally, in the Internet era, the emergence of a large number of online tourist enterprises and open platform, such as Ctrip, Tuniu, extends the conventional definition of tourist enterprises and place more emphasis on use of big data mining to meet customer need and provide better service.

At the same time, the tourist industry itself is a boundary-less industry. Big data allows the industry to grow in multiple directions on multiple platforms with multiple integrations. "Internet + " is a thought process of promoting the formation of cross-border and mutual integration and innovation. When creating integration innovation based with big data industry, tourist enterprises play the main role to support for the development of related industries and fields, identify new spaces for the development of tourist enterprises.

\section{References}

1. Frankel F, Reid R. Big data: Distilling meaning from data, J. Nature, 2008, 455(7209):30-30.

2. Anderson $\mathrm{C}$. The end of theory: The data deluge makes the scientific method obsolete, J. Wired Magazine, 2008, 16:1-3.

3. Donovan S. Dealing with data, J. Science, 2011, 331(6018):639-806.

4. James Manyika, Michael Chui. Big Data: The Next Frontier for Innovation, Competition and Productivity, J. McKinsey Quarterly, 2011, 5:38-47.

5. Brown, Brad, Chui, Michael, Manyika and James. Are You Ready for the Era of "Big Data", J. McKinsey Quarterly, 2011, 4:129-137.

6. Jeanne E. Johnson. Big Data + Big Analytics = Big Opportunities, J. Financial Executive,2012,7. 